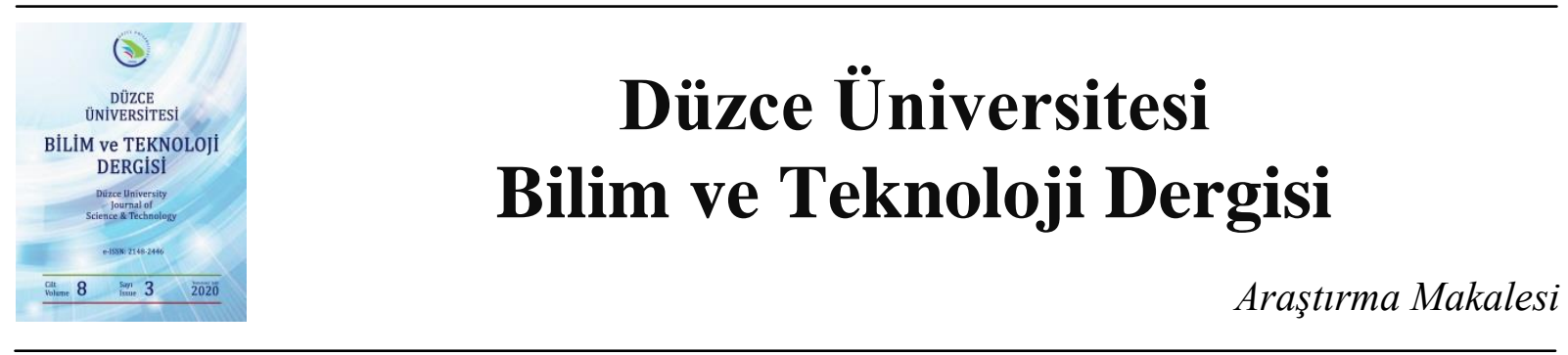

\section{Şeffaf bir PEM Yakıt Hücresinin Performansının Değerlendirilmesi}

\author{
Kadir GELİ̧̧ ${ }^{\mathrm{a}, *}$ \\ ${ }^{a}$ Makine Mühendisliği Bölümü, Mühendislik Fakültesi, Bolu Abant İzzet Baysal Üniversitesi, Bolu, TÜRKIYE \\ *Sorumlu yazartn e-posta adresi: kadirgelis@ibu.edu.tr
}

DOI: $10.29130 /$ dubited.692558

\begin{abstract}
ÖZET
Bu çalışmada PEM yakıt hücresinin katot gaz akış kanalında oluşan sıvı su damlacıklarını gözlemlemek için bir tarafı şeffaf olan bipolar plaka tasarımı yapılmıştır. Katot gaz akış kanalının şeffaf olarak imal edilmesi yakıt hücresi içinde oluşan su damlacığının gözlemlenebilmesini mümkün kılacaktır. İmalatı yapılan bipolar plaka malzemesinin gözlem imkânı sağlamasının yanı sıra elektron iletimini de sağlaması gerekmektedir. Bu yüzden; şeffaf yakıt pili oluşturmak için $1 \mathrm{~mm}$ kalınlı̆̆ında saç levha üzerine kanal tasarımı imal edilmiş ve saç levha üzerine $10 \mathrm{~mm}$ kalınlığında polikarbonat levha monte edilmiştir. Şeffaf olarak imal edilen yakıt pili deneysel performans sonuçları alüminyum levha üzerine imal edilen kanal tasarımının deneysel performans sonuçlarıyla kıyaslanmıştır. Sonuç olarak, şeffaf olmayan yakıt pili durumunda katalizör yüklemesi $0.3 \mathrm{mgPt} / \mathrm{cm}^{2}$ değerinden $0.5 \mathrm{mgPt} / \mathrm{cm}^{2}$ değerine yükseldiğinde $\left(0.6 \mathrm{~V}\right.$ değerinde) elde edilen akım yoğunluğu $114,2 \mathrm{~mA} / \mathrm{cm}^{2}$ den 276 $\mathrm{mA} / \mathrm{cm}^{2}$ ye yükselerek \%141,68 artış gösterirken, şeffaf olan yakıt hücresinde ise akım yoğunluğu $62,2 \mathrm{~mA} / \mathrm{cm}^{2}$ değerinden $120 \mathrm{~mA} / \mathrm{cm}^{2}$ değerine yükselerek \%92,9 artış göstermiştir. Bu sonuca göre katalizör yüklemesinin artışı ile şeffaf olmayan yakıt hücresinin etkinliğinin azaldığı sonucuna varılmıştır.
\end{abstract}

Anahtar Kelimeler: PEM yakıt pili, Şeffaf yaklt pili, slvı su oluşumu

\section{Evalution of a Transparent PEM Fuel Cell Performance}

\begin{abstract}
$\underline{\text { ABSTRACT }}$
In this study, a bipolar plate design with a transparent side was designed to observe the liquid water droplets formed in the cathode gas flow channel of the PEM fuel cell. The transparent production of the cathode gas flow channel will make it possible to observe the water droplet formed in the fuel cell. The manufactured bipolar plate material should provide electron transmission as well as observation. That's why; In order to create a transparent fuel cell, a channel design was produced on a $1 \mathrm{~mm}$ thick sheet metal and a $10 \mathrm{~mm}$ thick polycarbonate sheet was mounted on the sheet metal. The results of the experimental performance of the fuel cell manufactured transparently were compared with the experimental performance results of the duct design produced on the aluminum plate. As a result, when the catalyst loading increased from $0.3 \mathrm{mgPt} / \mathrm{cm}^{2}$ to $0.5 \mathrm{mgPt} / \mathrm{cm}^{2}$ (at 0.6 V) in the case of a non-transparent fuel cell, the current density obtained increased from $114.2 \mathrm{~mA} / \mathrm{cm}^{2}$ to 276 $\mathrm{mA} / \mathrm{cm}^{2}$, increasing $141.68 \%$, In the fuel cell, which is transparent, the current density increased from $62.2 \mathrm{~mA}$ $/ \mathrm{cm}^{2}$ to $120 \mathrm{~mA} / \mathrm{cm}^{2}$ and increased by $92.9 \%$. According to this result, it was concluded that the efficiency of the non-transparent fuel cell decreases with the increase of catalyst loading.
\end{abstract}

Keywords: Pem fuel cell, Transparent fuel cell, liquid water formation

Geliş: 21/02/2020, Düzeltme: 13/05/2020, Kabul: 20/05/2020 


\section{GİRIS}

Teknolojinin gelişmesi, aşırı artan sanayileşme ve konfor seviyesinin artışı ile birincil enerji kaynağı olan fosil yakıt rezervleri hızla tükenmeye başlamış ve enerjinin verimli kullanımı çok önemli bir konu haline gelmiştir. Tükenmeye yüz tutmuş fosil yakıtlar ve fosil yakıtların sebep olduğu çevre kirlenmesi insanları yeni enerji üretim yöntemlerine yöneltmiştir. Fosil yakıt rezervlerinin sınırlı olması ve her geçen gün kullanımlarının artışı fosil yakıtlara alternatif bulunmasını zorunlu hale getirmiştir. Enerji ihtiyacının her geçen gün artması ile birlikte yeni ve yenilenebilir enerji teknolojileri için Ar-Ge yatırımları artmaya devam etmektedir. Hidrojenden elektrik üretimini sağlayan yakıt pili teknolojisi de geleceğin yenilenebilir, temiz ve yüksek verimli enerji çözümü olarak kabul görmektedir [1]. PEM yakıt pilleri yüksek verim, düşük sıcaklıkta çalışma, yüksek güç yoğunluğu, hızlı başlatma ve sistem sağlamlığg nedeniyle hareketli ve sabit uygulamalar için sıfir emisyonlu güç kaynağı olarak umut vaad eden bir aday olduğunu vurgulamışlardır [2]. PEM yakıt pillerinin içerisinde gerçekleşen dinamik süreçlerin anlaşılması ve bu süreçlerin daha anlaşılır bir şekilde ifade edilmesi konu hakkında çalışma yapan bilim insanları için önem arz etmektedir. Bu sebeple Rahimi-Esbo ve arkadaşları akış kanallarının gözlemlenebildiği bir yakıt pili tasarlamış, tasarladıkları transparan yakıt pilinin tasarım, üretim, montaj ve test aşamalarını içeren bir çalışma sunmuşlardır [3]. Ghasemi ve arkadaşları yakıt pillerinde su yönetiminin performans açısından çok önemli olduğunu belirtmişlerdir [4].Carton ve arkadaşları PEM yakıt pilleri için su taşmasını içeren detaylı bir literatür taraması yapmış, gaz difüzyon tabakası ile damlacık oluşumu, hareketi ve etkileşimi kapsamlı olarak incelenmiştir [5]. Lee ve arkadaşları düşük sıcaklıkta çalışan PEM yakıt pillerinde yoğunlaşan suyun katalizör tabakası ve gaz difüzyon tabakasından uzaklaştırmanın zor olduğunu belirterek şeffaf olarak tasarladıkları yakıt pili ile bazı denemeler yapmışladır [6]. Aslam ve arkadaşları su taşması ve membran kurumasının PEM yakıt pillerinin performansını ve dayanıklılığını etkileyen iki ana unsur olduğunu vurgulamışlardır [7]. Pei ve arkadaşları yakıt pillerinde reaktantın giriş ve çıkışı arasındaki basınç farkı ile su taşması arasında ilişki kuran makaleleri incelemişlerdir [8]. Bachman ve arkadaşları reaktif gazın konsantrasyon değişimi ve kanal içerisindeki slug oluşumu arasında ilişki kurmaya çalışmışlardır [9]. Shimpalee ve arkadaşları PEM yakıt pillerindeki reaktant türlerinin konsantrasyonundaki dağılımlar yerel akım yoğunluğu, sıcaklık ve su içeriğinin PEMFC performansında etkili olduğu sonucuna varmışlardır [10]. Chen ve $\mathrm{Wu}$ yer çekiminin yakıt pili performansını araştırmak üzere kanalın yön ve açısını değiştirerek farklı nemlendirme koşullarına karşılık gelen polarizasyon eğrilerini elde etmişlerdir [11]. Kahveci ve Taymaz su ve 1sı yönetiminin hidrojen akış hızı, oksijen akış hızı, pil sıcaklığı ve nemlendirme sıcaklıklarının kontrol altında tutularak sağlanabileceğini vurgulamışlardır [12]. Manso ve arkadaşları PEM tipi yakıt pillerinin performansları çalışma koşulları, hücre içi taşınım olayları ve elektrokimyasal reaksiyonların kinetiği ve aynı zamanda bileşenlerin özellikleri gibi birç̧ok faktöre bağlı olduğunu vurgulamışlardır [13]. Wen ve arkadaşları PEM yakıt pili akış alanının optimizasyon parametrelerini; polarizasyon eğrisi, akım yoğunluğu dağılımı, oksijen dağılımı ve su kütlesi dağılımı olarak belirlemişlerdir [14]. Cooper ve arkadaşları birbirine kenetlenmiş(interdigitated) akış alanı tasarımı için nötron radyografisi sonuçları ile stokiyometri, kanal en/boy oranı ve su oluşumu arasında ilişki kurarak çıkarımlarda bulunmuşlardır [15]. Hu ve Cao serpantin tipi akış alanına sahip bir PEM yakıt pilinde değişen kanal derinliği ile kanal içerisinde oluşan su damlacığının etkisini gözlemleyebilmek amacıyla yakıt pilinin bir tarafını polikarbonat levha kullanarak şeffaf yapmışlardır [16]. Lim ve arkadaşları su yönetimi ve reaktan dağılımı üzerine çalışma yapan makaleleri incelemişlerdir [17]. Akhtar ve arkadaşları PEM yakıt pilinin akış kanallarındaki su damlacıklarının kinetik ve taşıma mekanizmalarını incelemişlerdir [18]. Banerjee ve arkadaşları basınç düşüşünün reaktant gazların kanallarındaki sıvı suyun varlığını belirlemek için iyi bir teşhis aracı olduğunu kabul etmişlerdir. Kanallardaki sıvı suyun varlığının kütle aktarım direncini artırdığını ve bu nedenle pil performansını artırdığını belirtmişlerdir [19]. Y. Li ve arkadaşları PEM yakıt pillerinde katot kısmının basınç düşümünün akış kanalındaki yakıt miktarı ile ilgili olduğunu ve basınç düşümü değerinin su yönetimi ile alakalı olduğunu belirtmişlerdir. Çalışmalarında yakıt piline giren gazın basıncı, empedans, pil sıcaklığı, nemlendirme ve basınç düşüşü ile su yönetimi arasında ilişki kurmuşlardır [20]. Wawdee ve arkadaşları akış alanı içerisinde su yönetimini geliştirmek amacıyla eğimli kanallar tasarlamışlardır ve bu tasarımlarını eğim olmayan 
dikdörtgen kanal ile kıyaslamışlardır. Eğimin aşağı yönlü ya da yukarı yönlü olması durumlarını su tahliyesi ile ilişkilendirerek çıkarımlarda bulunmuşlardır [21]. Ben Amara ve Ben Nasrallah su yönetiminin PEM yakıt pili ile ilgili problemlerden birisi olduğunu, yakıt pillerinde nem performansının önemli olduğunu ve protonların verimli bir şekilde taşınabilmesi için zarın yeterince nemlendirilmesi gerektiğini söylemişlerdir [22]. Wang ve arkadaşları gözenekli bir hidrofilik su taşıma plakasını (Water Transport Plate ) PEM tipi yakıt pillerinde su yönetimini geliştirmek için bipolar plaka olarak kullanmışlardır ve yapmış oldukları deneylerin sonucunda hidrofilik su taşıma plakalarının yakıt pilinin katot kısımda kullanımının su yönetimi iyileştirmesinde umut verici olduğunu göstermiştir [23]. Heidary ve arkadaşları akış kanalları içerisindeki suyun tıkanması ile pil performansının değişeceğini belirtmişlerdir [24]. Hou ve arkadaşları PEM yakıt pilinin katot kısmında oluşan suyu gidermek için çalışmalar yapmışlardır ve kanal malzemesinin hidrofilik / hidrofobik olmasının da su hareketi ile ilişkisi olduğu sonucuna varmışlardır [25]. PEM yakıt pillerinde reaktant gazların dağılımı, akım yoğunluğu dağılımı, sıcaklık dağılımı ve su konsantrasyonunun önemli olduğunu[26], bu parametrelerin muntazam olmaması durumunda MEA'nın ömrünün kısalacağını vurgulamışlardır [27]. Vasifeshenas ve arkadaşları se birleşik akış alanı tasarımının su taşması olayını önlemek için umut vaad eden bir gelişme olduğunu söylemişlerdir [28]. Literatürde kanal içerisindeki su oluşumu ile performans arasında ilişki kuran çeşitli sayısal çalışmalarda mevcuttur. Bu çalışmalar elektrokimyasal süreçler ile su taşınımı arasında ilişkiler kurmuşlardır [29,30,31,32,33]. Kim ve arkadaşları Forchheimer'in atalet etkisinin ilk kez 3 boyutlu karmaşık akış alanlarındaki sıvı su davranışı ve kütle taşınımının altında yatan sebepleri aydınlatmak amacıyla PEM yakıt pillerinin üç boyutlu kompleks akış alanlarının iki aşamalı bir modelini geliştirmişlerdir [34].

Bu çalışmada PEM yakıt hücresi akış alanı içerisinde oluşan su damlacığını gözlemlemek amacı ile şeffaf bir yakıt hücresi tasarlanmıştır. Şeffaf olarak tasarlanan yakıt hücresinin polarizasyon eğrisi çıktıları aynı deney şartlarında test edilen şeffaf olmayan yakıt hücresi polarizasyon eğrisi sonuçları ile kıyaslanarak çıkarımlarda bulunulmuştur.

\section{MATERYAL VE METOT}

\section{A. YAKIT PİLI ÇALIŞMA PRENSIBiI}

Bir yakıt pilinde anot tarafından gaz yakıtlar, katot tarafindan ise oksitleyici gazlar verilir. Anot kısmında yükseltgenme, katot kısmında ise indirgenme reaksiyonları gerçekleşir. Toplam reaksiyon sonucunda ürün olarak su, 1sı ve elektrik çıkar. Elektrotlar arasında bulunan elektrolitte ise anottan katoda doğru bir iyon geçişi gerçekleşir [35]. Şekil 1' de yakıt pili için temel çalışma prensibi verilmiştir.

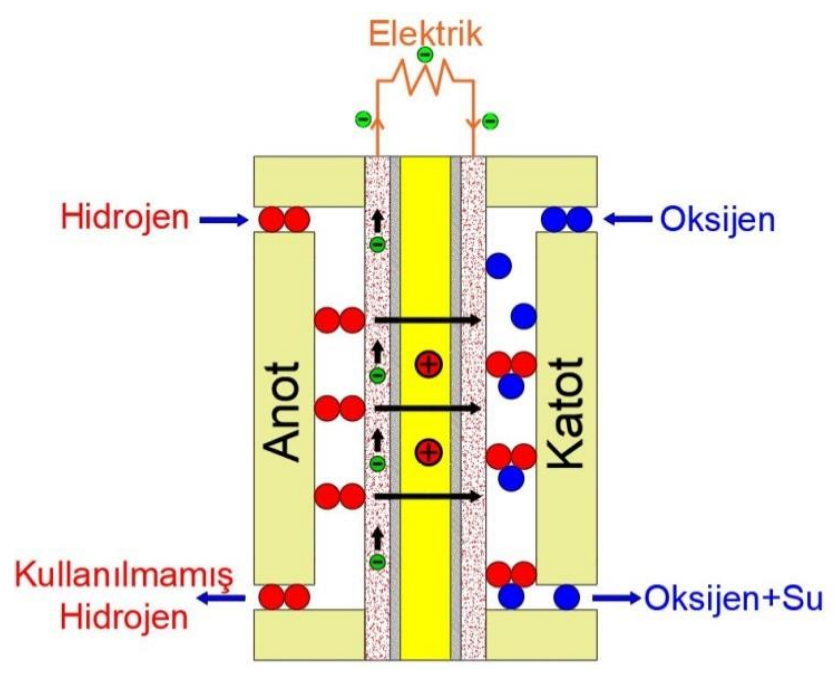


Şekil 1.Yakit pili temel çalı̧̧ma prensibi

Yakıt pilinin anot kısmında oluşan reaksiyon (hidrojen):

$H_{2} \rightarrow 2 H^{+}+2 e^{-}$

(Hidrojen yükseltgenme reaksiyonu)

Yakıt pilinin katot kısmında oluşan reaksiyon (oksijen);

$\frac{1}{2} \mathrm{O}_{2}+2 \mathrm{H}^{+}+2 e^{-} \rightarrow \mathrm{H}_{2} \mathrm{O}$

(Oksijenin indirgenme reaksiyonu)

Tüm hücrede gerçekleşen toplam reaksiyon:

$\mathrm{H}_{2}+\frac{1}{2} \mathrm{O}_{2} \rightarrow \mathrm{H}_{2} \mathrm{O}$

Şeklindedir. Bu reaksiyonlar çeşitli ara basamaklar içerebilir.

PEM yakıt pillerine hidrojen ve oksijen girer; 1s1, su ve elektrik açığa çıkar. Şekil 2'de yakıt pillerinin çalışma sistematiği sunulmuştur.

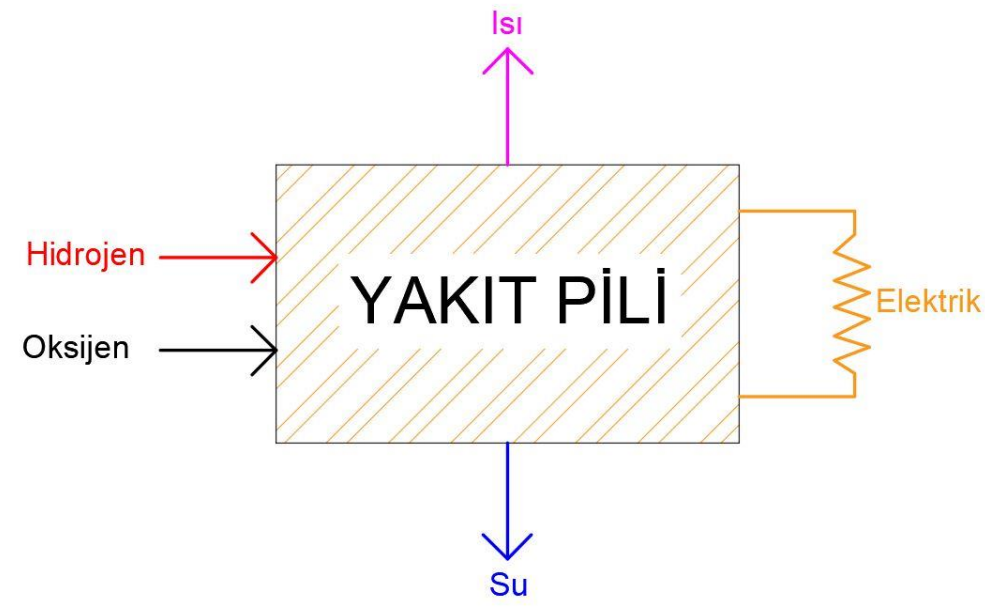

Şekil 2. Yakut pili sistematiği

$\mathrm{Bu}$ çalışmada yakıt pillerinin performansını karakterize etmek için, elektrokimyasal bir teknik olan polarizasyon eğrileri kullanılmıştır. Polarizasyon eğrileri elde edildiği zaman yakıt pilinin o işletme koşulları altında uğradığı performans kayıplarına dair bilgi verir. Deneysel performans sonuçları alınırken uygulanan işletme şartları Tablo 1 de verilmiştir.

Tablo 1. Deneysel İşletme Koşulları

\begin{tabular}{ll}
\hline Parametre & İşletme Koşulu \\
\hline Pil Sıcaklığı & $50^{\circ} \mathrm{C}$ \\
\hline Nemlendirme Sicaklığı & $50{ }^{\circ} \mathrm{C}$ \\
\hline Hidrojen Debisi & $0.3 \mathrm{lt} / \mathrm{dk}$ \\
\hline Oksijen Debisi & $0.2 \mathrm{lt} / \mathrm{dk}$
\end{tabular}


Çalışmada kullanılan yakıt pili performans testleri Şekil 3' te görülen, Erzurum Atatürk Üniversitesi Kimya Mühendisliği Bölümü'nde bulunan Henatech ${ }^{\mathrm{TM}}$ marka (max $600 \mathrm{~W}$ ) yakıt pili test istasyonu sistemi kullanılarak alınmıştır.

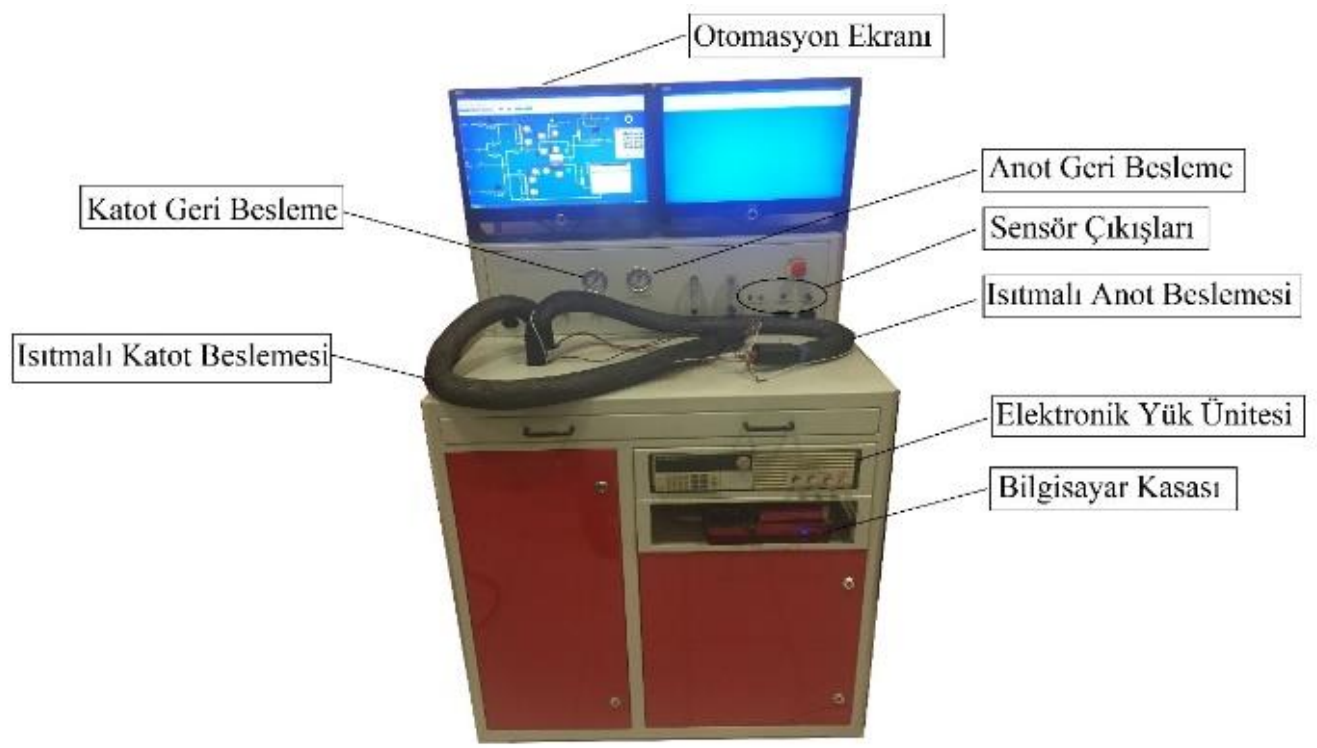

Şekil 3. Yakıt pili test istasyonu

\section{B. TASARIM VE IMMALAT SÜRECI}

PEM yakıt pillerinin ana bileşenleri anot akım toplama plakası, anot bipolar plaka, membran elektrot grubu, sizdırmazlık contaları, katot bipolar plaka, katot akım toplama plakası ve 1sitıcilardır. Yakıt pillerinin temel bileşenleri Şekil 4' de, PEM yakıt pilinin temel yapısı ise Şekil 5'de verilmiştir.

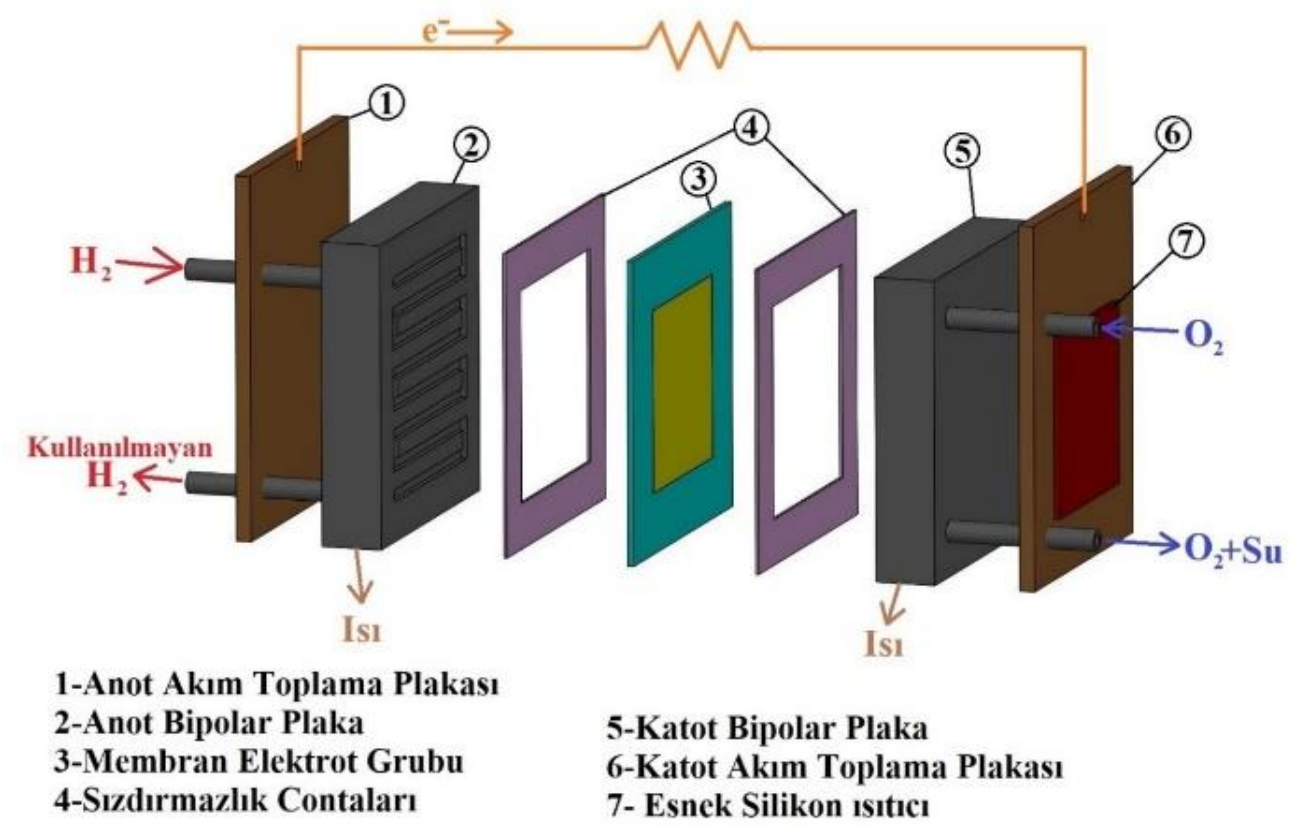

Şekil 4. PEM Yakut pili bileşenleri 


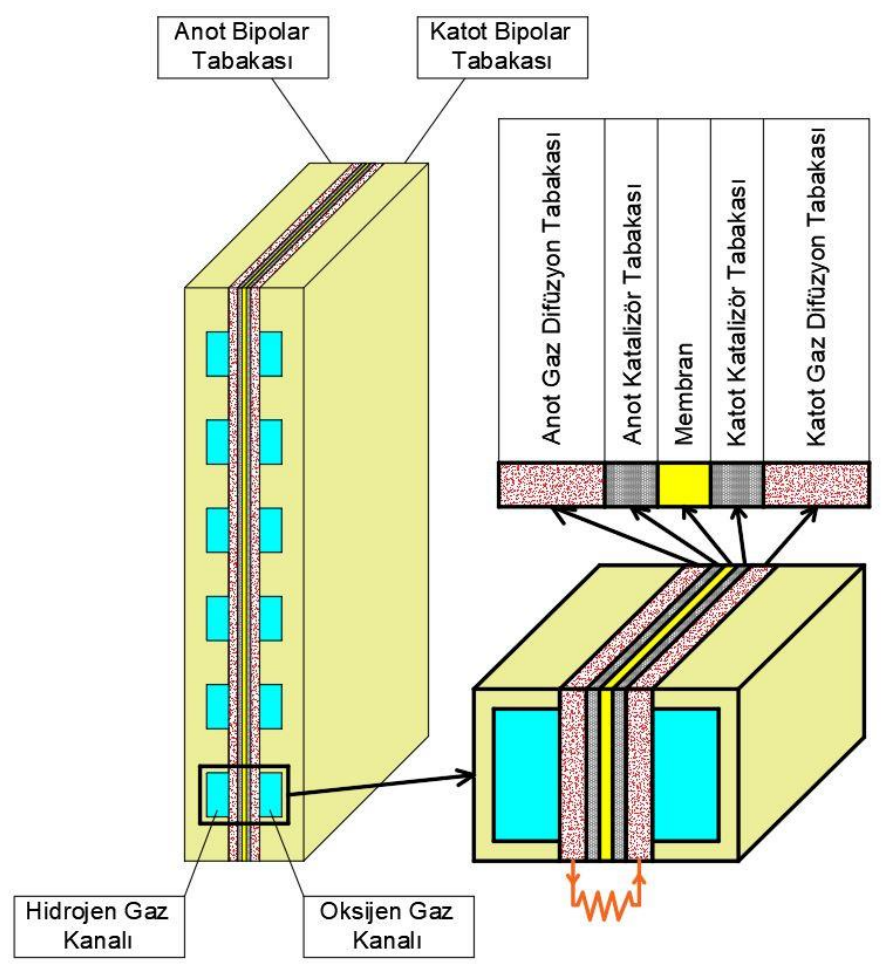

Şekil 5. PEM yakut pili yapısı

$\mathrm{Bu}$ çalışma kapsamında imalatı yapılan bipolar plaka tasarımları CNC Freze yardımıyla imal edilmiştir. Hem şeffaf hem de alüminyum olarak imal edilen tasarımların aktif alanları $50 \mathrm{~cm}^{2}$ dir.(7.1 $\mathrm{cm} \times 7.1 \mathrm{~cm}$ ) Her iki tasarım içinde kanal genişliği $2 \mathrm{~mm}$, kanal derinliği $1 \mathrm{~mm}$ dir. Deneylerde fuelcellstore firmasından temin edilen $0.5 \mathrm{mg} \mathrm{Pt} / \mathrm{cm}^{2}$ ve $0.3 \mathrm{mg} \mathrm{Pt} / \mathrm{cm}^{2}$ katalizör yüklemesinde membran elektrot grubu kullanılmıştır. Anot ve katot kısımları alüminyum olarak imal edilen yakıt pilinin perspektif görüntüsü ve bipolar plaka üzerine imal edilen tekli serpantin tipi akış alanı tasarımının görüntüsü ise Şekil 6'da verilmiştir.

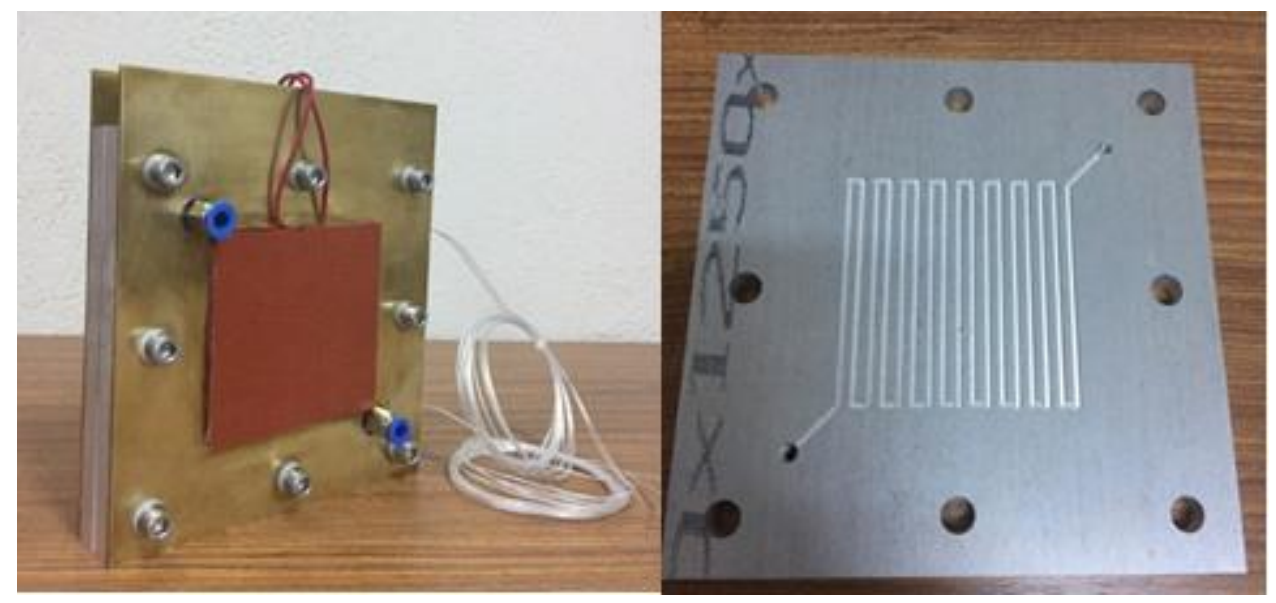

Şekil 6. Yakıt pilinin perspektif görünüşü ve tekli serpantin tipi akış alanı

Kanal içerisinde oluşan sıvı suyu gözlemlemek amacıyla Katot kısmı şeffaf olarak imal edilen yakıt pili tasarımı ise Şekil 7'de verilmiştir. Şeffaf olarak tasarlanan yakıt pilinin yandan görünüşü Şekil 8 'de verilmiştir. 


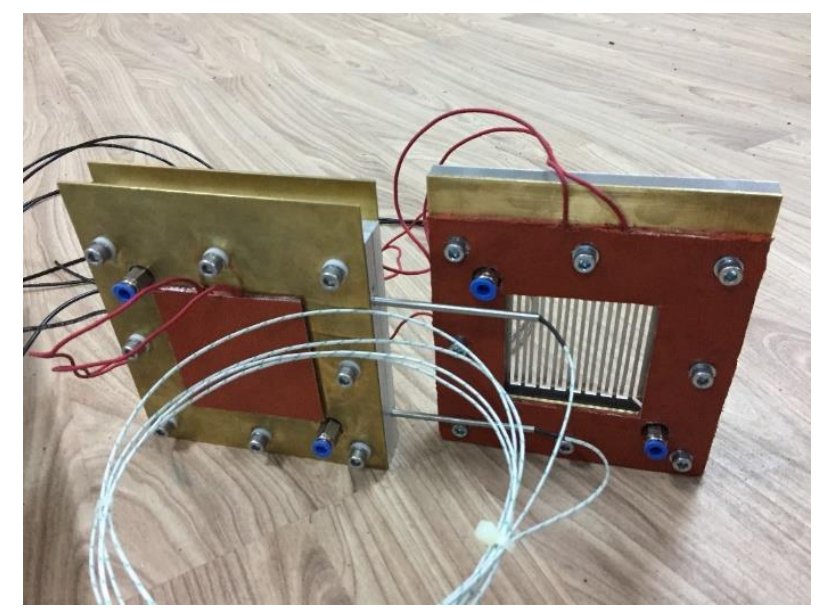

Şekil 7. Bir tarafi şeffaf yakıt pili tasarımı

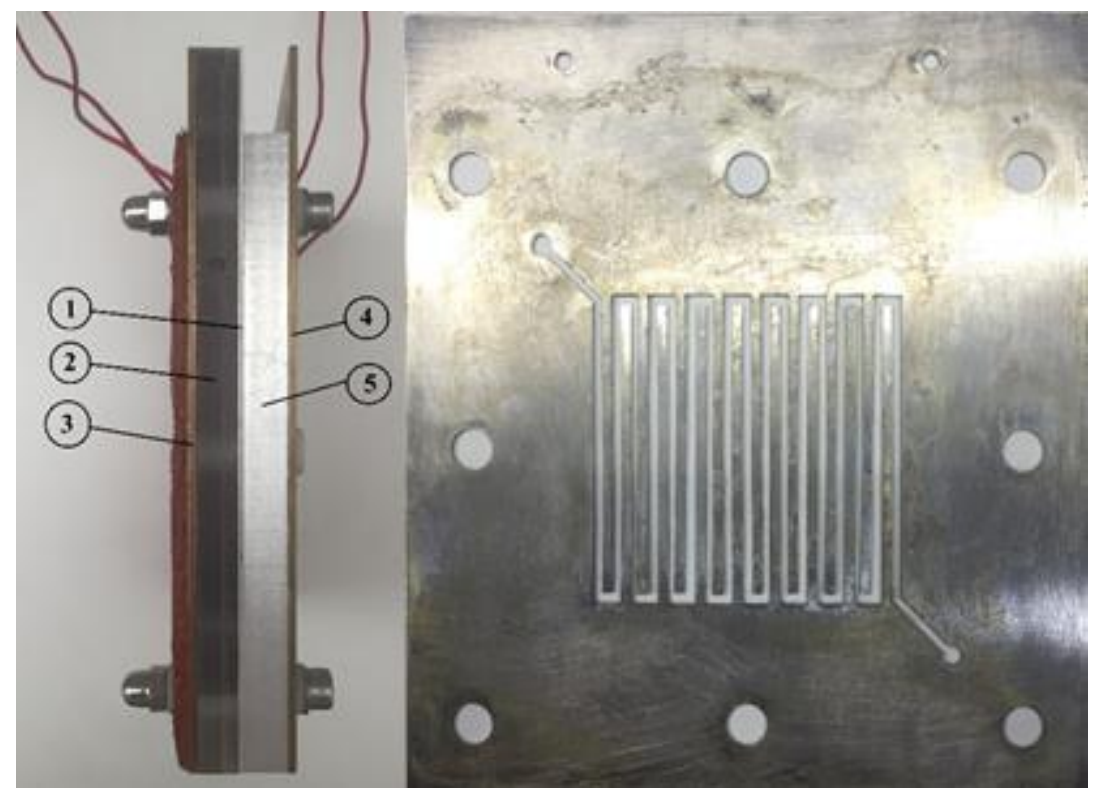

Şekil 8. Şeffaf yakıt pilinin bileşenleri

Şekil 8' de verilen görselde 1 numaralı parça aynı şekil içerisinde sağ tarafta görülen CNC lazer ile kesilmiş $1 \mathrm{~mm}$ kalınlığında alüminyum levha, 2 numaralı parça $10 \mathrm{~mm}$ kalınlığında tasarıma uygun olarak kesilmiş olan polikarbonat levha, 3 numaralı parça ise katot kısmı akım toplama plakası, 4 numaralı parça anot akım toplama plakası ve 5 numaralı parça ise Şekil 7'de resmi verilmiş olan üzerine serpantin tip kanal tasarı işlenmiş alüminyum bipolar plakadır.

\section{BULGULAR VE TARTISMA}

Membranın kuruması proton iletkenliğini düşürürken, aşırı nemlendirme ise kanallarda su taşmasına sebep olmaktadır, bu durumda kanalların tıkanıp gaz geçişine engel olmakta yani reaksiyonun durmasına sebep olmaktadır [36]. Bu sebeple akış kanalı içerisinde oluşan suyun gözlemlenebilir olması ve nasıl bir davranış sergilediğinin anlaşılması çok önemlidir. 


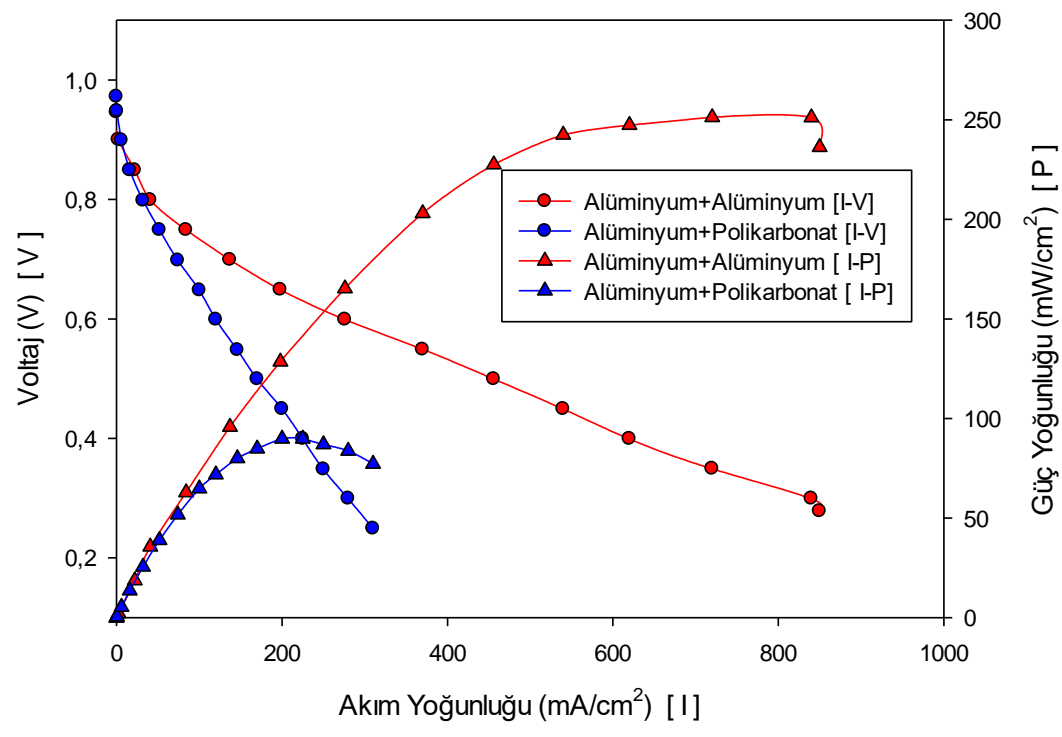

Şekil 9. Şeffaf ve şeffaf olmayan yaktt pili polarizasyon eğrileri $\left(0.5 \mathrm{mgPt} / \mathrm{cm}^{2}\right)$

$0.5 \mathrm{mgPt} / \mathrm{cm}^{2}$ katalizör yüklemesine sahip şeffaf ve şeffaf olmayan bipolar plakaların akım yoğunluğuvoltaj-güç yoğunluğu ilişkisini veren grafik Şekil 9'da sunulmuştur. Şekilden de anlaşılacağı üzere; her iki tasarım içinde aynı membran elektrot grubu kullanılmasına rağmen şeffaf ve şeffaf olmayan yakıt pillerinin deneysel performansları aynı değildir. Alüminyum+ alüminyum tasarıma sahip yakıt pili $0.6 \mathrm{~V}$ değerinde $276 \mathrm{~mA} / \mathrm{cm}^{2}$ akım yoğunluğuna ulaşmışken; alüminyum+ polikarbonat tasarıma sahip yakıt pili $0.6 \mathrm{~V}$ değerinde $120 \mathrm{~mA} / \mathrm{cm}^{2}$ akım yoğunluğuna ulaşmıştır.

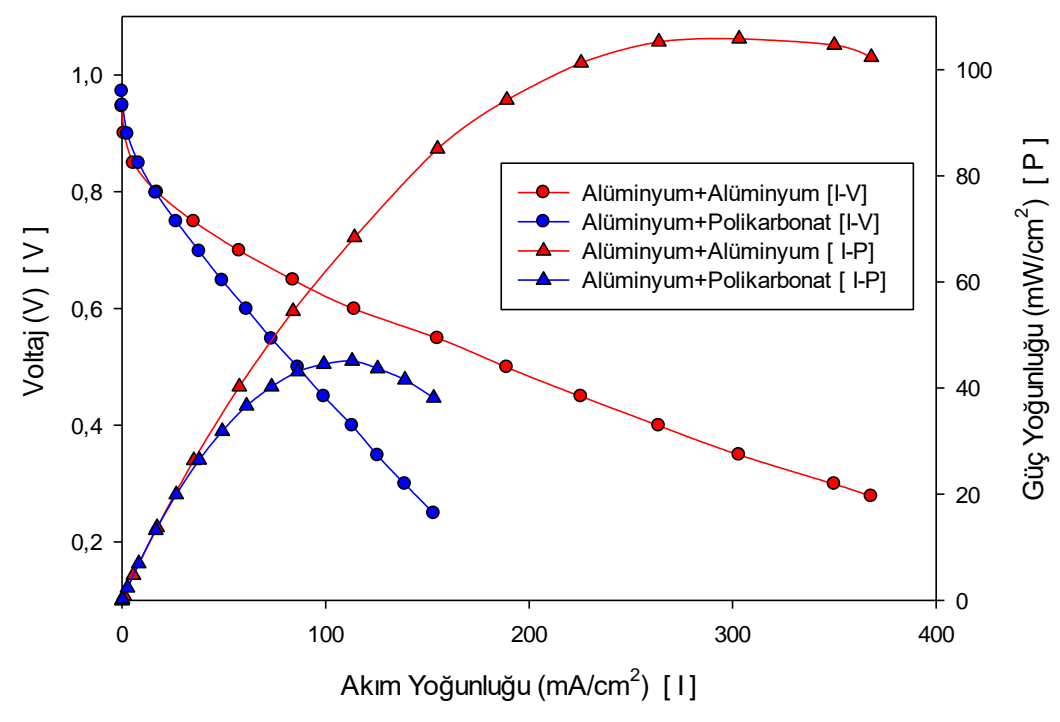

Şekil 10. Şeffaf ve şeffaf olmayan yakıt pili polarizasyon eğrileri $\left(0.3 \mathrm{mgPt} / \mathrm{cm}^{2}\right)$

$0.3 \mathrm{mgPt} / \mathrm{cm}^{2}$ katalizör yüklemesine sahip şeffaf ve şeffaf olmayan bipolar plakaların akım yoğunluğuvoltaj-güç yoğunluğu ilişkisini veren grafik Şekil 7 de sunulmuştur. Şekilden de anlaşılacağı üzere; her iki tasarım içinde aynı membran elektrot grubu kullanılmasına rağmen şeffaf ve şeffaf olmayan yakıt pillerinin deneysel performansları aynı değildir. Alüminyum+ alüminyum tasarıma sahip yakıt pili 0.6 
$\mathrm{V}$ değerinde $114,2 \mathrm{~mA} / \mathrm{cm}^{2}$ akım yoğunluğuna ulaşmışken; alüminyum+ polikarbonat tasarıma sahip yakıt pili $0.6 \mathrm{~V}$ değerinde $62,2 \mathrm{~mA} / \mathrm{cm}^{2}$ akım yoğunluğuna ulaşmıştır.

\section{IV.SONUC}

$\mathrm{Bu}$ çalışmada katot kısmı şeffaf olarak tasarlanan yakıt pili ile şeffaf olmayan yakıt pilinin performansları kıyaslanmıştır. Çalışma kapsamında tekli serpantin tipi kanal tasarımı şeffaf ve şeffaf olmayan yakıt pili şeklinde üretilmiş ve deneysel performansları değerlendirilmiştir. Her iki tasarım için $0.5 \mathrm{mgPt} / \mathrm{cm}^{2}$ ve $0.3 \mathrm{mgPt} / \mathrm{cm}^{2}$ katalizör yüklemeleri durumunda I-V ve I-P grafikleri çizilmiş elde edilen sonuçlar aşağıda maddeler halinde verilmiştir:

- Şeffaf olmayan yakıt pili tasarımı için $\left(0.3 \mathrm{mgPt} / \mathrm{cm}^{2}\right) 0.6 \mathrm{~V}$ değerinde $114,2 \mathrm{~mA} / \mathrm{cm}^{2}$ akım yoğunluğu elde edilmişken; aynı işletme şartları altında şeffaf olmayan yakıt pilinden $62,2 \mathrm{~mA} / \mathrm{cm}^{2}$ akım yoğunluğu elde edilmiştir.

- Şeffaf olmayan yakıt pili tasarımı için $\left(0.5 \mathrm{mgPt} / \mathrm{cm}^{2}\right) 0.6 \mathrm{~V}$ değerinde $276 \mathrm{~mA} / \mathrm{cm}^{2}$ akım yoğunluğu elde edilmişken; aynı işletme şartları altında şeffaf olmayan yakıt pilinden $120 \mathrm{~mA} / \mathrm{cm}^{2}$ akım yoğunluğu elde edilmiştir.

- Şeffaf olmayan yakıt pili durumunda katalizör yüklemesi $0.3 \mathrm{mgPt} / \mathrm{cm}^{2}$ değerinden $0.5 \mathrm{mgPt} / \mathrm{cm}^{2}$ değerine yükseldiğinde ( $0.6 \mathrm{~V}$ değerinde) elde edilen akım yoğunluğu $114,2 \mathrm{~mA} / \mathrm{cm}^{2}$ den 276 $\mathrm{mA} / \mathrm{cm}^{2}$ ye yükselerek $\% 141,68$ artış gösterirken, şeffaf olan yakıt hücresinde ise akım yoğunluğu $62,2 \mathrm{~mA} / \mathrm{cm}^{2}$ değerinden $120 \mathrm{~mA} / \mathrm{cm}^{2}$ değerine yükselerek \%92,9 artış göstermiştir. Bu sonuca göre katalizör yüklemesinin artışı ile şeffaf olmayan yakıt hücresinin etkinliğinin azaldığı sonucuna varılmıştır. Bunun sebebi yüksek katalizör yüklemelerinde oluşan akım yoğunluğunun artışı ile şeffaf olan yakıt hücresinin elektron taşıyabilme kapasitesinin yetersiz kalmasıdır.

- Yüksek katalizör yüklemelerinde deney yapıldıkça şeffaf olmayan yakıt hücresi sonucu şeffaf olan yakıt hücresi sonuçlarından uzaklaşmaktadır. Bu metot ile düşük Pt yüklemeli katalizör içeren yakıt hücrelerinin modellenmesi ve akış alanı içerisinde oluşan dinamik süreçlerin anlaşılması mümkündür.

TEȘEKKÜR: Bu çalışma Atatürk Üniversitesi Kimya Mühendisliği Labaratuvar Altyapısı kullanılarak tamamlanmıştır. Çalışmalarım esnasında bana destek olan Prof. Dr. Bayram Şahin ve Prof. Dr. Ayşe Bayrakçeken YURTCAN'a teşekkürü borç bilirim.

\section{KAYNAKLAR}

[1] K. Geliş, "Farklı akış alanı tasarımlarının yakıt pili performansına etkisinin deneysel ve sayısal incelenmesi," Doktora tezi, Makine Mühendisliği Bölümü, Erzurum Teknik Üniversitesi, Erzurum, Türkiye, 2019.

[2] X. Li and I. Sabir, "Review of bipolar plates in PEM fuel cells: Flow-field designs," Int. J. Hydrogen Energy, vol. 30, no. 4, pp. 359-371, 2005.

[3] M. Rahimi-Esbo, A. Ramiar, A. A. Ranjbar and E. Alizadeh, "Design, manufacturing, assembling and testing of a transparent PEM fuel cell for investigation of water management and 
contact resistance at dead-end mode," Int. J. Hydrogen Energy, vol. 42, no. 16, pp. 11673-11688, 2017.

[4] M. Ghasemi, A. Ramiar, A. A. Ranjbar and S. M. Rahgoshay, "A numerical study on thermal analysis and cooling flow fields effect on PEMFC performance," Int. J. Hydrogen Energy, vol. 42, no. 38, pp. 24319-24337, 2017.

[5] J. G. Carton, V. Lawlor, A. G. Olabi, C. Hochenauer and G. Zauner, "Water droplet accumulation and motion in PEM (Proton Exchange Membrane) fuel cell mini-channels," Energy, vol. 39, no. 1, pp. 63-73, 2012.

[6] N. W. Lee, S. Il Kim, Y. S. Kim, S. H. Kim, B. K. Ahn and M. S. Kim, "An effective discharge method for condensed water inside the GDL using pressure gradient of a PEM fuel cell," Int. J. Heat Mass Transf., vol. 85, pp. 703-710, 2015.

[7] R. M. Aslam, D. B. Ingham, M. S. Ismail, K. J. Hughes, L. Ma and M. Pourkashanian, "Simultaneous thermal and visual imaging of liquid water of the PEM fuel cell flow channels," $J$. Energy Inst., vol. 92, pp. 1-8, 2018.

[8] P. Pei, Y. Li, H. Xu and Z. Wu, "A review on water fault diagnosis of PEMFC associated with the pressure drop," Appl. Energy, vol. 173, pp. 366-385, 2016.

[9] J. Bachman, M. Charvet, A. Santamaria, H. Y. Tang, J. W. Park and R. Walker, "Experimental investigation of the effect of channel length on performance and water accumulation in a PEMFC parallel flow field," Int. J. Hydrogen Energy, vol. 37, no. 22, pp. 17172-17179, 2012.

[10] S. Shimpalee, V. Lilavivat, J. W. Van Zee, H. McCrabb and A. Lozano-Morales, "Understanding the effect of channel tolerances on performance of PEMFCs," Int. J. Hydrogen Energy, vol. 36, no. 19, pp. 12512-12523, 2011.

[11] S. Chen and Y. Wu, "Gravity effect on water discharged in PEM fuel cell cathode," Int. J. Hydrogen Energy, vol. 35, no. 7, pp. 2888-2893, 2010.

[12] E. E. Kahveci and I. Taymaz, "Experimental investigation on water and heat management in a PEM fuel cell using response surface methodology," Int. J. Hydrogen Energy, vol. 39, no. 20, pp. 10655-10663, 2014.

[13] A. P. Manso, F. F. Marzo, J. Barranco, X. Garikano and M. Garmendia Mujika, "Influence of geometric parameters of the flow fields on the performance of a PEM fuel cell. A review," Int. J. Hydrogen Energy, vol. 37, no. 20, pp. 15256-15287, 2012.

[14] D. hui Wen, L. zhi Yin, Z. yu Piao, C. da Lu, G. Li and Q. hui Leng, "Performance investigation of proton exchange membrane fuel cell with intersectant flow field," Int. J. Heat Mass Transf., vol. 121, pp. 775-787, 2018.

[15] N. J. Cooper, A. D. Santamaria, M. K. Becton and J. W. Park, "Investigation of the performance improvement in decreasing aspect ratio interdigitated flow field PEMFCs," Energy Convers. Manag., vol. 136, pp. 307-317, 2017.

[16] M. Hu and G. Cao, "Research on the performance differences between a standard PEMFC single cell and transparent PEMFC single cells using optimized transparent flow field unit-Part I: Design optimization of a transparent flow field unit," Int. J. Hydrogen Energy, vol. 41, no. 4, pp. 2955-2966, 2016.

[17] B. H. Lim, E. H. Majlan, W. R. W. Daud, T. Husaini and M. I. Rosli, "Effects of flow field 
design on water management and reactant distribution in PEMFC: a review," Ionics (Kiel)., vol. 22, no. 3, pp. 301-316, 2016.

[18] N. Akhtar, A. Qureshi, J. Scholta, C. Hartnig, M. Messerschmidt and W. Lehnert, "Investigation of water droplet kinetics and optimization of channel geometry for PEM fuel cell cathodes," Int. J. Hydrogen Energy, vol. 34, no. 7, pp. 3104-3111, 2009.

[19] R. Banerjee, D. Howe, V. Mejia and S. G. Kandlikar, "Experimental validation of two-phase pressure drop multiplier as a diagnostic tool for characterizing PEM fuel cell performance," Int. J. Hydrogen Energy, vol. 39, no. 31, pp. 17791-17801, 2014.

[20] Y. Li $v d$., "Approaches to avoid flooding in association with pressure drop in proton exchange membrane fuel cells," Appl. Energy, vol. 224, no. February, pp. 42-51, 2018.

[21] P. Wawdee, S. Limtrakul, T. Vatanatham and M. W. Fowler, "Water transport in a PEM fuel cell with slanted channel flow field plates," Int. J. Hydrogen Energy, vol. 40, no. 9, pp. 3739-3748, 2015.

[22] M. E. A. Ben Amara and S. Ben Nasrallah, "Numerical simulation of droplet dynamics in a proton exchange membrane (PEMFC) fuel cell micro-channel," Int. J. Hydrogen Energy, vol. 40, no. 2, pp. 1333-1342, 2015.

[23] Z. Wang, Y. Zeng, S. Sun, Z. Shao and B. Yi, "Improvement of PEMFC water management by employing water transport plate as bipolar plate," Int. J. Hydrogen Energy, vol. 42, no. 34, pp. 21922-21929, 2017.

[24] H. Heidary, M. J. Kermani, A. K. Prasad, S. G. Advani and B. Dabir, "Numerical modelling of in-line and staggered blockages in parallel flowfield channels of PEM fuel cells," Int. J. Hydrogen Energy, vol. 42, no. 4, pp. 2265-2277, 2017.

[25] Y. Hou, G. Zhang, Y. Qin, Q. Du and K. Jiao, "Numerical simulation of gas liquid two-phase flow in anode channel of low-temperature fuel cells," Int. J. Hydrogen Energy, vol. 42, no. 5, pp. 3250-3258, 2017.

[26] M. Rahimi-Esbo, A. A. Ranjbar, A. Ramiar, E. Alizadeh and M. Aghaee, "Improving PEM fuel cell performance and effective water removal by using a novel gas flow field," Int. J. Hydrogen Energy, vol. 41, no. 4, pp. 3023-3037, 2016.

[27] E. Alizadeh, M. Rahimi-Esbo, S. M. Rahgoshay, S. H. M. Saadat and M. Khorshidian, "Numerical and experimental investigation of cascade type serpentine flow field of reactant gases for improving performance of PEM fuel cell," Int. J. Hydrogen Energy, vol. 42, no. 21, pp. 14708-14724, 2017.

[28] Y. Vazifeshenas, K. Sedighi and M. Shakeri, "Numerical investigation of a novel compound flow-field for PEMFC performance improvement," Int. J. Hydrogen Energy, vol. 40, no. 43, pp. 15032-15039, 2015.

[29] V. Lilavivat, S. Shimpalee, J. W. Van Zee, H. Xu and C. K. Mittelsteadt, "Current Distribution Mapping for PEMFCs," Electrochim. Acta, vol. 174, pp. 1253-1260, 2015.

[30] E. Afshari, M. Ziaei-Rad and M. M. Dehkordi, "Numerical investigation on a novel zigzagshaped flow channel design for cooling plates of PEM fuel cells," J. Energy Inst., vol. 90, no. 5, pp. 752-763, 2017.

[31] T. F. Cao, H. Lin, L. Chen, Y. L. He and W. Q. Tao, "Numerical investigation of the coupled 
water and thermal management in PEM fuel cell," Appl. Energy, vol. 112, pp. 1115-1125, 2013.

[32] J. Nie and Y. Chen, "Numerical modeling of three-dimensional two-phase gas-liquid flow in the flow field plate of a PEM electrolysis cell," Int. J. Hydrogen Energy, vol. 35, no. 8, pp. 31833197, 2010.

[33] E. Mancusi, É. Fontana, A. A. Ulson De Souza and S. M. A. Guelli Ulson De Souza, "Numerical study of two-phase flow patterns in the gas channel of PEM fuel cells with tapered flow field design," Int. J. Hydrogen Energy, vol. 39, no. 5, pp. 2261-2273, 2014.

[34] J. Kim, G. Luo and C. Y. Wang, "Modeling two-phase flow in three-dimensional complex flow-fields of proton exchange membrane fuel cells," J. Power Sources, vol. 365, pp. 419-429, 2017.

[35] M. U. Karaoğlan ve N. S. Kurulay, "Pem yakit hücresi modeli," Mühendis ve Makina, c. 55, s. 657, ss. 51-58, 2014.

[36] B. Yılmaz, "Polimer elektrolit membranlı yakıt pilleri için anot üretimi," Yüksek Lisans tezi, Makine Mühendisliği Bölümü, İstanbul Teknik Üniversitesi, İstanbul, Türkiye, 2006. 